\title{
EVALUATION OF ANTIBACTERIAL ACTIVITY OF VOLATILE OIL FROM MENTHA SPICATA L.
}

\section{*Chauhan Shailendra Singh, Agarwal Ruchi}

Department of Chemistry, College of Basic Science and Humanities, G.B. Pant University of Agriculture and Technology, Pantnagar, India

*Corresponding author email address: - shailu.chauhan1@gmail.com

\begin{abstract}
Volatile oil from the herbs of Mentha spicata L. (family Lamiaceae) were extracted from ten different natural habitats of Uttarakhand and their antibacterial potential was analyzed. Leaves oil were extracted by hydro distillation using Clavenger's apparatus. The oil yield varied from $0.57 \%-1.4 \%$. The essential oil rich in carvone and piperitone oxide were exploited for determining antibacterial potentials by disc diffusion assay. These oils showed antibacterial activities against three gram negative (Salmonella enterica enterica, Escherichia Coli and Pasturella multocida) and one gram positive (Staphyllococcus aureus) bacteria with varying magnitudes. Volatile nature of plant essential oils can be explored drugs for prevention and treatment of pathogenic diseases.

Key words: Mentha spicata L., antibacterial and volatile oil
\end{abstract}

\section{INTRODUCTION}

Family Lamiaceae a rich source of terpenoids consists of 264 genera and 6,990 species distributed world over ${ }^{1}$. The Indian sub-continent represents 72 genera and 435 species $^{2}$. Indian Himalayan region is a big repository of the family Lamiaceae. Western Himalaya represents 60 genera and 225 species $^{3}$. Himachal Pradesh represents 42 genera and 111 species $^{4}$, while Uttarakhand region contributes 49 genera and 151 species of Lamiaceae ${ }^{5}$ out of total species reported in India. The most common and popular mints for cultivation are peppermint (Mentha piperita), spearmint (Mentha spicata) and apple mint (Mentha suaveolens). Spearmint (Mentha spicata, locally known as domestic mint/ Pudina) is an important herb used for various human remedy. Essential oils have been shown to possess antibacterial, antifungal, antiviral, insecticidal and antioxidant proprieties 6,7 . In view of pharmacological activity and Industrial potentiality to use the essential oil of M.spicata, it is necessary to check the chemical variation in the essential oils of M.spicata grown in different climatic habitats. The present study was undertaken to analyze the antimicrobial potentials of volatile oils obtained from Mentha spicata L. from different climatic habitates.

\section{MATERIALS AND METHODS}

\section{Plant material}

The herbs of spearmint (Mentha spicata L.) belonging to family Lamiaceae were collected from different natural habitats viz. Khatima, Rishikesh, Almora, Tanakpur, Kashipur, Nainital, Champawat, Pithoragarh, Haldwani and Harinagar of Uttarakhand.

\section{Extraction of essential oils}

Fresh aerial part of each collection of Mentha spicata L. was subjected to Clevenger's type apparatus for 8 hours. Extraction of essential oils was distillate by diethyleter or dichloromethane followed by drying over anhydrous sodium sulfate. The oil samples were stored at $0^{\circ} \mathrm{C}$ in airtight vessels. The essential oil composition of aerial parts of $M$. spicata collected from different locations of
Uttarakhand, were analyzed by the combination of GC and GC-MS techniques ${ }^{8}$. The essential oils which were carvone rich and piperitone oxide rich, was used for determining antibacterial potentials by disc diffusion assay.

\section{Test Microorganisms}

The antibacterial screening against four pathogenic microorganisms including three gram negative (Salmonella enterica enterica, Escherichia Coli and Pasturella multocida) and one gram positive (Staphyllococcus aureus) was performed. Nutrient agar (NA) and Nutrient broth (NB) were obtained from Hi Media, Ltd, Mumbai and prepared as per manufactures instructions. Antibacterial screening of the essential oils against these bacteria was done by Disc-diffusion method with slight modification 9 .

\section{Antibacterial assay}

The disc diffusion method was employed for screening the antibacterial properties of isolated volatile oil. Autoclaved nutrient agar when cooled to $45^{\circ} \mathrm{C}$ was poured into sterilized Petri plates containing nearly $20 \mathrm{~mL}$ agar medium in laminar flow. After solidification, these Petri plates were incubated at $37^{\circ} \mathrm{C}$ overnight for sterile testing. Pure cultures of test bacteria were prepared by emulsifying five colonies in $5 \mathrm{~mL}$ sterilized nutrient broth. Tubes with nutrient broth and inoculated bacterial cultures were incubated overnight at $37^{\circ} \mathrm{C}$ for $24 \mathrm{hrs}$. Next day cultures showed a marked turbidity in the tubes were used. Bacterial suspension of $0.1 \mathrm{~mL}$ of (10times diluted) was added to previously prepare nutrient agar plate and bacterial strain was thoroughly spread on the agar surface, using bent rod. Under aseptic conditions, empty sterilized discs (Whatman no. 5, $6 \mathrm{~mm}$ diameter) were impregnated with $20 \mu \mathrm{l}$ of two different concentrations (1:1 and 1:5) of respective volatile oils and placed on the agar surface. These inoculated plates were firmly closed with the maximum possible aseptic precautions. A standard disc containing gentamicin was used as a reference control. The 
plates were left for $30 \mathrm{~min}$ at room temperature to allow the diffusion of oil and then incubated at $37^{\circ} \mathrm{C}$ for $24 \mathrm{hrs}$. The antimicrobial activity was evaluated by measuring the zone of inhibition against each of the test bacterial species. All experiments were carried in triplicates.

\section{RESULTS AND DISCUSSION}

The yield of essential oils from the herbs of Mentha spicata obtained by hydrodistillaton varied from $0.57 \%$ $1.4 \% \mathrm{v} / \mathrm{w}$. The essential oils of plants were found dominated by piperetenone oxide from the sites Tanakpur and Kashipur in $79.2 \%$ and $60.6 \%$ respectively. The essential oils of plants collected from sites Champawat and Harinagar were dominated by carvone by $68.5 \%$ and $66.8 \%$ of oils, respectively) ${ }^{8}$. The antibacterial activity of these carvone and piperetenone oxide essential oils were evaluated against selected bacteria is summarized in table 1. DMSO control disc not showed any activity.

Plant essential oils and extracts have been used from thousands of years in food preservation, pharmaceuticals, alternative medicines and natural therapies ${ }^{10,11}$. However, scientific investigation of plants used in traditional medicine is essential to improve their quality and healthcare benefits. Essential oils are potential source of novel antimicrobial agents especially against bacterial pathogens $^{12}$. In contrast to antibiotics, essential oils are highly volatile at room temperature, thus can be used for inhalation therapy in respiratory tract infections ${ }^{13}$.

The present study showed that all the volatile oils showed activity against Escherichia coli and Salmonella enterica enterica. The essential oil from collection site Tanakpur did not showed activity against Salmonella enterica enterica and Pasturella multocida. The maximum zone of inhibition was found in essential oil from collection site Tanakpur, Kashipur and Champawat against Escherichia coli, while the maximum zone of essential oil from collection site Harinagar was observed against Pasturella multocida. Minimum zone of inhibition as observed in the essential oil from collection site Tanakpur, Kashipur and Harinagar against Salmonella enterica enterica and collection site Champawat against Staphyllococcus aureus. To evaluate the antibacterial activity against pathogenic bacteria the antibiotic Gentamicine was used as standard. The result showed that the essential oil exhibits antibacterial activity. The zone of inhibition of essential oils and Gentamicin were presented in Table 1.

Table 1: Antibacterial activity of different extracted volatile oils using disc diffusion method

\begin{tabular}{|c|c|c|c|c|c|c|c|c|c|}
\hline Microorganism & \multicolumn{8}{|c|}{ Collection site of Mentha spicata in Uttarakhand, India } & \multirow{3}{*}{ Gentamicin } \\
\hline \multirow{2}{*}{ Bacteria } & \multicolumn{2}{|c|}{ I } & \multicolumn{2}{|c|}{ II } & \multicolumn{2}{|c|}{ III } & \multicolumn{2}{|c|}{ IV } & \\
\hline & 1:1 & $1: 5$ & 1:1 & 1:5 & 1:1 & 1:5 & 1:1 & $1: 5$ & \\
\hline Escherichia coli & $14 \pm 0.6$ & $8 \pm 0.7$ & $13 \pm 0.5$ & $9 \pm 0.2$ & $15 \pm 0.8$ & $9 \pm 0.7$ & $15 \pm 0.6$ & $8 \pm 0.5$ & $20 \pm 0.4$ \\
\hline $\begin{array}{c}\text { Salmonella enterica } \\
\text { enterica }\end{array}$ & $10 \pm 0.8$ & $6.8 \pm 0.5$ & $8 \pm 0.6$ & 5 & 9 & $4 \pm 0.5$ & $9 \pm 0.9$ & $3 \pm 0.6$ & $14 \pm 0.2$ \\
\hline Pasturella multocida & $12 \pm 1.0$ & $9 \pm 0.9$ & $14 \pm 0.7$ & $6 \pm 0.6$ & $(-)$ & $(-)$ & $13 \pm 0.8$ & $7 \pm 0.7$ & $17 \pm 0.3$ \\
\hline Staphyllococcus aureus & $9 \pm 1.1$ & $6 \pm 0.4$ & $10 \pm 0.4$ & $7 \pm 0.5$ & $(-)$ & $(-)$ & $13 \pm 0.7$ & $5 \pm 0.9$ & $15 \pm 0.6$ \\
\hline
\end{tabular}

Note: Values in the table are zone of inhibition, are measured in millimeter and expressed as mean $\pm S D$

(-) sign indicates no zone of inhibition

$I=$ Champawat, $I I=$ Harinagar, $I I I=$ Tanakpur and $I V=$ Kashipur

\section{CONCLUSIONS}

The development of antibiotic resistance in human pathogens creating the problems in treatment of diseases using antibiotics, herbal drugs showing antimicrobial

\section{REFERENCES:}

1. Thorne RF. An updated classification of the class Magndioprida (Angiospermae). Botanical Review, 2007, 73(2), 67-182.

2. Kartikeyan S and Singh NP. Flora of India, introductory volume part-II, Botanical survey of India; 2000. P. 201-217.

3. Rana TS, Nath B and Datt, B. A census of the family Lamiaceae syn. Labiatae in Western Himalaya, Higher Plant. Indian Subcast; 1997, 6, 31-55.

4. Chowdhery HJ and Wadhwa MB. Flora of Himachal Pradesh vol.-II, BSI Howrah; 1984.

5. Uniyal BP, Sharma JR, Choudhary U and Singh DK. Flowering plants of Uttarakhand (A Check list); 2007.

6. Burt S. Essential oils: their antibacterial proprieties and potential application in food. Journal of Applied Microbiology, 2004, 94, 223-253.

7. Kordaly S, Kotan R, Mavi A, Cakir A, Ala A and Yildirim A. Determination of the chemical composition and antioxidant activity of the essential oil of Artemisia dracunculus and of the antifungal and antibacterial activities of Turkish Artemisia absinthium, A dracunculus, Artemisia santonicum and Artemisia spicigera essential oils. Journal of Agricultural and Food Chemistry, 2005, 53, 9452-9458. potentials can be considered as effective alternative for antibiotics. Due to volatile nature essential oils are the drugs for prevention and treatment of diseases. Hence it can be concluded that the Mentha spicata L. essential oils can be a good source of natural antibacterial agent.

8. Chauhan SS, Prakash O, Padalia RC, Vivekanand, Pant AK and Mathela CS. Chemical Diversity in Mentha spicata: Antioxidant and Potato Sprout Inhibition activity of its Essential oils. Natural Product Communication, 2011, 6 (9), 1373-1378.

9. Singh G, Marimuthu P, Murali HS and Bawa AS. Antioxidant and antibacterial potential of essential oils and extracts isolated from various spice materials. Journal of Food Safety, 2005, 25, 130-145.

10. Prabuseenivasan $S$, Jaykumar $M$ and Igancimuthu $S$. In vitro antibacterial activity of some plant essential oils. BMC Compl Alter Med., 2006, 6, 39.

11. Bansod S and Rai M. Antifungal activity of essential oils from Indian medicinal plants again human pathogenic Aspergillus fumigates and A. niger. World J Med Sci., 2008, 3(2): 81-88.

12. Mitscher LA, Drake S, Gollapudi SR and Okwute SK. A modern look at folkoric use of anti-infective agents. J Nat Prod., 1987, 50, 1025-1040.

13. Inouye $\mathrm{S}$, Takizawa $\mathrm{T}$, Yamaguchi H. Antibacterial activity of essential oils and their major constituents against respiratory tract pathogens by gaseous contacts. J. Antimicrobial Chemother., 2001, 47, 565-573. 